\title{
Reminiscences of the last 50 years and the way forward
}

This article is a retrospective and a prospective look at $S A L$ on the occasion of its $50^{\text {th }}$ anniversary. The founding editors and various editors reflect on their experiences.

\section{HOW S.A.L. CAME INTO BEING}

\section{T. Givón (Founder \& First Editor) University of Oregon}

When I went to Africa to do my dissertation field-work in 1967, I was a brash budding Bantuist and ex biologist, having taken Des Cole's Comparative Bantu course when he visited us at UCLA the previous year. My choice of Bemba as my field language led me to a courtesy call to Malcolm Guthrie at SOAS, where I was obliged to spend a leisurely semester in the fall of 1967, taking African history and anthropology classes; which the Ford Foundation, my kind sponsors, considered me deficient at. Prof. Guthrie invited me to his plush country estate, where he deigned to inform me that I should not bother to study Bemba because he and his star student, Michael Mann, had already said anything there was to be said about it. Just before I was slated to leave for Zambia, I got a note from Bob Stockwell, longtime chair of the UCLA linguistics department, which a few years before absorbed the African Language section of the Near Eastern and African Languages department. "We might have to hire you as our Comparative Bantuist" he wrote, "a new position we just got approved. But you'll have to finish your dissertation by July 1969".

The UCLA department had converted whole hog to Chomskian linguistics ca. 1963, a year before I started my graduate work there, absorbing Bob Stockwell and Paul Schachter (my dissertation chair) from English, Bill Welmers and two more Africanists from Near Eastern Languages, and Peter Ladefoged and Vicki Fromkin from the Phonetics Lab. It went on then to cram itself chockful of certified Generativists from MIT and elsewhere. When I joined the faculty in July 1969, all these teachers became my colleagues.

The Zeitgeist at UCLA at the time can be summarized by Paul Postal's, an early acolyte of Chomsky, apocryphal dictum: "A universal of language is a feature that can be found in at least one language, preferably". All theory development took place in that one language (guess which). And 'theory' was largely synonymous with the reigning formalism. Joe Greenberg's intellectual program on the balance between cross-language diversity and language universals was not yet on the map, flying under the Generative radar.

Working under Stockwell's tight deadline, I still managed to work on four more Bantu languages in Zambia in addition to Bemba. I also managed to get a strong whiff of how the British Colonial expats controlled not only the academic institutions in eastern and southern Africa, my presumed Bantu province, but also the main publication venues for African languages, which cared little for general linguistics, typology or universals. Bloomfield's aversion to judging a language by any except its own peculiar terms was widely shared by the reigning experts; though Des Cole was still kind enough to publish my first paper, on the morpho-phonemics of the Bantu verbal suffixes, in his journal, African Studies. 
This is the intellectual background vis-a-vis which, in my first year on the UCLA faculty, I began lobbying my colleagues for starting a new journal of African linguistics; a journal that would consider the diversity of African languages--but in the wider a theoretical context; which at the time was still strongly equated with Chomskian Generative Grammar. What I brought to the enterprise was the predictable mix of youthful enthusiasm and profound ignorance. But I was apparently careful enough not to alienate the core formalists in the department. And the UCLA African Studies Center was kind enough to give us a minimal budget and the use of a corner of an office. I wound up doing most of the typing myself (yeah, all those typos!); I invented a secretary and signed her name to the business correspondence; my Africanist colleagues at the department became my editorial board and manuscript reviewers. The first issue came out in the Fall of 1970, and contained Herb Stahlke's seminal article "Serial Verbs".

Somehow, it worked. We slowly got enough subscribers, becoming a home for the homeless. Our shoestring operation and ragged printing and binding were somehow tolerated, or kindly forgiven. My colleagues on the editorial board let me get away with, practically, murder. Soon, however, the very seeds of what got me interested to begin with began to erode my interest. On the Bantu side, all those beautiful languages of Southern and Eastern Africa began to look more and more alike. Having looked at a few more myself and having supervised a few Bantu dissertations, I was beginning to experience the same boredom that drove me out of Biochemistry in 1964. What is more, the Chomskian paradigm I was expected to hew to began to look less and less tenable. Above all, language diversity beyond Africa beckoned.

I used my first sabbatical in 1972-73 to escape to Colorado, where I discovered the Ute people and their language. I gave the editorship to Larry Hyman for that year, then took it back in 1973. But my heart was not in Africa any more. When the chance to work with Joe Greenberg on his Universals Project at Stanford came up in the fall of 1975, I grabbed it, giving Thomas Hinnebusch the journal editorship for good. The following year, having started a long-term project on the Ute language in Colorado, I informed my colleagues that Bantu and Africa were just too restrictive for me. I wanted to do linguistics full time. They expressed their disappointment, but having made the mistake of granting me tenure in 1974, they had lost their most serious leverage. In retrospect, the founding of SAL was an early attempt to integrate the incredible diversity of African languages into the study of universals of human language. Since I have not kept up with the journal since quitting, I have no idea whether that early vision is still reflected in the current journal. The fact that SAL has survived for fifty years may or may not be a vindication of an old dream, rooted in Kant's philosophy of science, that facts without theory are blind, while theory without facts is empty.

\section{Larry Hyman (Editor, 1972-1973) University of California, Berkeley}

I am very happy to provide this reminiscence of the early days of Studies in African Linguistics. I remember the founding editor, Talmy Givón, informing me of his plans to establish the journal and inviting me as a graduate student to be on the editorial board and to submit something for the first issue. It was an honor to publish the lead article in vol. 1.1, "On the role of borrowing in the justification of phonological grammars" (Hyman 1970). Two years later, as an assistant professor at the University of Southern California, I was editor of four issues of the UCLA journal from 1972 to 1973 (vols. 3.2, 3.3, 4.1, 4.2), subsequently stepping down to take up a two-year postdoc up in Berkeley. Talmy Givón's original idea was that $S A L$ would represent the best in African linguistics, both in the traditional areas of description, history and comparison, but also with respect to what 
African languages have to say about language in general. It was an exciting time when generative grammar was developing and Africanists were probing the theoretical significance of typologically salient properties of African languages, e.g. serial verbs, noun classes, tone etc. During my stint as editor a number of seminal articles appeared which continue to have impact on the field. Perhaps the article that I am the most proud of publishing is Paul Newman's (1973) "Syllable weight as a phonological variable" in vol. 3.3. Drawing heavily from Chadic languages, syllable weight had not been adequately recognized in phonological circles. (See Newman 2017, Syllable weight in African languages, John Benjamins, for a recent collection on the same topic.) Another pair of articles in vol. 4.1 by Voorhoeve (1973) and Schadeberg (1973) brought to our attention the "restricted tone systems" of the Bantu languages Safwa and Kinga, which continue to be cited in studies in wordprosodic typology. This was an exciting time of discovery and debate. During my editorship we published the Heny-Givón-Heny exchange (vols. 3.2, 3.3) concerning whether adjectives were a separate category from nouns in Bantu (see also Bennett's "Heny vs. Givón: Pardon: may I cut in?" in vol. 4.2), Hyman's (1973) "Notes on the history of Southwestern Mande" (vol. 4.2) addressing the Welmers-Bird disagreement on reconstructing the third person singular bound pronoun, and Williamson's "More on nasals and nasalization in Kwa" (1973, vol. 4.2) further commenting and expanding on my article "Nasals and nasalization in Kwa" (Hyman 1972, vol. 3.2). Besides notes and responses, the early issues of SAL also included conference reports. All of this can be seen in the scanned issues in the archive on the SAL website (https://journals.flvc.org/sal/issue/archive). Givón also initiated an SAL supplement series that published conference proceedings as well as monographs, e.g. the dissertations of the first two editors which appeared as supplements \#3 (Givón 1972 Studies in Icibemba and Bantu grammar) and \#4 (Hyman 1972, A phonological study of fe'fe'-bamileke). It is a pity that the roughly 10 (?) supplements are not available on the website, e.g. supplement \#6, Papers in African linguistics in honor of Wm. E. Welmers, the distinguished Africanist - and our teacher (Hyman, Jacobson \& Schuh, eds, 1976). Going back over these issues reminds me of the excitement of African linguistics in the early days of $S A L$ which continues both in later and current pages of this journal and in other journals that followed in $S A L$ 's footsteps.

\section{Thomas Hinnebusch and Russell Schuh (Editors, 1973-1991) University of California, Los Angeles}

Thomas Hinnebusch joined T. Givón as joint editor in 1973. This is what he shared. "I read T. Givón's report. I liked the background which gives the context and motivation behind starting SAL. And it brought to mind the British-trained linguists I interacted with when I was doing my field work. In any case, and maybe Larry can help with this. I was T. Givón's student at UCLA and joined the faculty in Fall 1973. Like him, I also had to have my dissertation finished before I could be legally hired. I was in Kenya doing my field work and expecting to take 2 years doing that and writing the dissertation. Halfway through the first year Robert Stockwell wrote asking me to apply for the open Swahili position. So I finished the damn thing, field work and all in 6 months!). Anyway I'm not back at UCLA very long, teaching 3 classes and supervising and training two teaching assistants, that first quarter, before T. Givón asks me to take over the editorship of SAL".

One of the major problems we faced getting SAL published was the preparation of the camera-ready copy for the printers. It was a huge headache. Having an IBM Selectric typewriter with specialized, changeable, phonetic font elements helped a great deal in accommodating nonEnglish alphabets and phonetic script. The self-correcting ribbon also helped streamline the 
process. Even so some of our early typists were perfectionists and it was difficult to convince them that correcting fluid - so-called "white-out"-- worked well too in correcting typos. It wasn't until I was able to hire Claudia, my wife, and bring everything home that the whole operation improved substantially. Also without other UCLA staff to help with art work and negotiating with printers it would have been an impossible task. Today, with computers the editing task has to be imminently easier than it was when Talmy started the the journal.

Another annoying problem, though not frequent, was the wounded egos of authors who were unhappy with the comments of external reviewers or even my suggestions for improving the manuscript. I always relied on external reviewers - the editorial board members - for questions dealing with content or argumentation. I restricted myself to matters of style and constraints on length and similar matters. Even so, I was once accused of conspiring with a reviewer when I asked an author to shorten an overly written, verbose, and lengthy article by 4 or 5 pages. I don't think the author ever accepted my explanation that my request had nothing to do with a different academic point-of-view about an interpretation of data. Over all, my stint as editor was a positive experience and it afforded me an opportunity to sharpen my own abilities as a researcher and writer. When Russ agreed to help and then take over the job himself I must confess I was relieved."

Thomas was co-editor with T. Givón till 1974 (Vol 5:3) when he became sole editor. He was joined by Russell Schuh as joint editor in 1975 during the publication of the 3 rd issue. The two worked together till 1979 when Russell became sole editor. Russell continued thus till 1991 when he was joined by Robert Botne. Russell was therefore the longest-serving editor of SAL. Larry recalls his written comment on one of his typewritten submissions when he discovered that two successive examples had the same number. He writes: 'I can't remember how he put it, but it was funny. Something like, "Have fun! Renumbering time!"’ Russell passed away on November 8, 2016. (https://linguistics.ucla.edu/russell-schuh/)

\section{Robert Botne (Editor, 1991-2002) Professor Emeritus, Indiana University}

I came to SAL in 1991 to join Russ Schuh as co-Editor, just after being appointed Assistant Professor in Linguistics at Indiana University. At that point, the journal was moribund, not having appeared for a couple of years, Volume 20:3 (1989) having been the last issue published. What had been a vibrant and intellectually stimulating forum for both descriptive and theoretical work on African languages during the previous 20 years was seemingly fading out of existence. Russ and I developed a plan to work together to get several of the manuscript submissions that had accumulated quickly reviewed and published. Nevertheless, this took some time, and Volume 21:1 (dated 1990) did not appear until early 1992; Volume 22:1 (dated 1991) did not appear until 1993. In order to get the journal back in alignment with the calendar, the three issues of Volume 23 were dated 1992-1994, published in 1994.

Due to the gap in publication, submissions had declined significantly and it became necessary to reduce the frequency of publication from three to two issues per year, beginning with the condensed Volume 23 (1992-1994), at which point the journal was back on track, just in time to celebrate its $25^{\text {th }}$ Anniversary, and take on a new cover design. After 25 years, the field of linguistics had changed significantly. Where little attention had been accorded African languages in 1970and the need for a special journal was essential - by 1995 articles incorporating African language data and structures into linguistic theory and language typology were fairly common in the more general linguistic journals. One could legitimately ask if there was a continuing need for a journal with an African areal focus. Of course, there was. The journal continued to publish descriptions and analyses of language data from a wide variety of African languages, work that would not readily 
have found a place in more theoretically inclined journals. It continues, I believe, to represent an important nexus within the community of African language scholars, providing a public forum for specialists in the field, and a focal point for collegial and professional discourse.

\section{David Odden (Editor 2003-2009) \\ Emeritus Professor, Ohio State University \& Affiliate Professor, University of Washington}

I took over SAL from 2003 to 2009 (vol. 32-37), though the cover dates reflected optimism rather than the calendar by about a year. The challenge which we faced, as Bob Botne faced, was the low number of submissions. Since at the time the journal was entirely print-based, articles had to be distributed in fixed batches, meaning that the works in hand needed to be sufficient to justify going to press. In retrospect, it might have been better to publish slimmer but more timely volumes. Recruiting submission was a particular challenge, since publication venues for African linguistics had substantially expanded compared to the early days of the journal. An attempt was made to encourage parallel submission of sound files for online distribution, which was realized in the final issue under my tenure with Michael Marlo's article on Tura tone, but after the fact when the server hosting the file was removed, it became clear that online distribution also faced a significant challenge of permanency.

\section{Tucker Childs and Jedd Schrock (Editor and Editorial Assistant, 2009 - 2018)}

Tucker Childs was editor of SAL from 2009-2018 (vol. 38-47). Tucker asked me to be his assistant in this endeavor. Tucker readily embraced his role as editor, working diligently at his SAL duties for the duration, though I know he was weary of it by the end. All of you who have assumed this role know this weariness. My job was to help with proof-reading, printing, mailing, and managing subscriptions.

This was the period when SAL changed to print-and-online distribution. Migrating to an online format was both hopeful and worrying. The possibilities of providing global open-access to the corpus of SAL articles seemed a very worthy goal. At that point SAL was financially selfsustaining with a well-tended list of subscribers. It was uncertain what open-access would do to the subscribership and future of SAL. But on we went.

I had the privilege of digitizing all those SAL articles. I'm the kind of weirdo who likes such tasks. David Odden had mailed all the old, dusty volumes of SAL to us. It was quite a pile! Tucker found an office for me in one of the buildings that Portland State had slated for demolition-I felt right at home. A few months later when demolition was imminent, I extracted ten copies of each volume to keep as holdings. The rest were jettisoned. I moved our holdings to my house. I still encounter the occasional silverfish in my basement whose ancestors feasted on SAL binding glue and ink. Volumes were taken to a local printer to cut off the bindings. The pages then got fed through my trusty, old Canon Pixma MX310. Feeding scans was the perfect engagement for a new dad whose son still napped three times a day. I borrowed any missing volumes via InterLibraryLoan and scanned those, too. Then there was the creation, extracting, labeling and uploading of individual articles from volume pdfs. I believe I completed the whole run with the exception of Supplements 1-6 which were unavailable via ILL. Anyone still have those laying around somewhere?

Tucker (Saa Chakporma) died this past January. The field of African Linguistics has lost a very good friend. He is very much missed. (https://www.pdx.edu/applied-linguistics/memorytucker-childs). 


\section{James Essegbey, Brent Henderson and Fiona McLaughlin (Editors, 2018-present) University of Florida}

We took over from Tucker and Jedd in October of 2018, with James Essegbey as editor-in-chief, and Brent Henderson and Fiona McLaughlin as co-editors. The plan is to rotate the position of editor-in-chief every three years. The first thing we did was meet with our colleagues at the University of Florida Libraries to discuss publishing SAL with Florida Online Journals. This required migrating the journal to a new website on Florida Online Journals (https://journals.flvc.org/sal), using Open Journal Systems (OJS) from the Public Knowledge Project (PKP). The process took Tucker's open access endeavor a step further to increase accessibility of the journal. It also brought the journal into compliance with institutional standards for open access.

Since $S A L$ had been published on the Linguistic Society of America (LSA) website and on a standalone site for many years, migrating the journal to the new system was a huge task. We had to reconstruct a database of 48 years of $S A L$ publishing for importation. This task was performed by Brent Henderson with the assistance of Bill Dyer, who is a graduate students in Linguistics. In June 2019, Florida Online Journals upgraded from OJS 2 to OJS 3. We have been assisted immensely, first, by Suzanne Stapleton and, after her, Chelsea Johnston from the UF Libraries. In 2021, Chelsea helped us to apply for inclusion in the Directory of Open Access Journals (DOAJ) community.

There are many benefits to the new system, including the fact that authors can track the status of their paper from the time they submit it to the time it is published. Information on how to submit their papers can be accessed at https://journals.flvc.org/sal/about/submissions. We encourage authors to read the submission information under Author Guidelines. In order to ensure a double-blind review, it is crucial that authors do not upload their information in the same document as their abstract and the manuscript.

Although we started receiving papers in 2018, Tucker and team published the final issue of 2018 and we published the first volume on Florida Online Journals in 2019. We decided at the beginning to publish six papers per issue, and to follow the tradition we inherited of publishing two issues per year. While the online issues would appear in April and September, the two would be bound together as a single hard volume at the end of the year. Although when we started we did not think we would publish book reviews, we decided to start doing so with the 49:2 issue.

The biggest challenge we have faced so far is getting reviewers. While a few colleagues very generously accepted prompts to review when asked, many decline to do so. That is unfortunate because the quality of $S A L$ papers is dependent on our reviewers. Many times, we have to contact several reviewers before one accepts to review a paper. This has delayed the turnaround time, a problem that has been exacerbated by the pandemic. We thank all our authors, subscribers and readers for your infinite patience with us. Above all, we thank our colleagues who have promptly answered our invitation to review papers for us.

We hope that $S A L$ will have a home here at the University of Florida for many years to come and continue its strong legacy of making linguistic work on African languages prominent and accessible for everyone. 